\title{
Research
}

Fiona M Walter, A Toby Prevost, Linda Birt, Nicola Grehan, Kathy Restarick, Helen C Morris,

Stephen Sutton, Peter Rose, Sarah Downing and Jon D Emery

\section{Development and evaluation of a brief self-completed family history screening tool for common chronic disease prevention in primary care}

\begin{abstract}
Background

Family history is an important risk factor for many common chronic diseases, but it remains underutilised for diagnostic assessment and disease prevention in routine primary care.
\end{abstract}

\section{Aim}

To develop and validate a brief self-completed family history questionnaire (FHQ) for systematic primary care assessment for family history of diabetes, ischaemic heart disease, breast cancer and colorectal cancer.

\section{Design and setting}

Two-stage diagnostic validation study in 10

general practices in eastern England.

\section{Method}

Participants aged $18-50$ years were identified via random sampling from electronic searches of general practice records. Participants completed a FHQ then had a three-generational 'gold standard' pedigree taken, to determine disease risk category. In stage 1, the $F H Q$ comprised 12 items; in stage 2 the shorter 6-item FHQ was validated against the same 'gold standard'.

\section{Results}

There were 1147 participants (stage 1: 618; stage 2: 529). Overall, $32 \%$ were at increased risk of one or more marker conditions /diabetes $18.9 \%$ ischaemic heart disease $13.3 \%$, breast cancer $6.2 \%$, colorectal cancer $2.2 \%$ ). The shorter 6-item $\mathrm{FHQ}$ performed very well for all four conditions: pooled data from both stages show diabetes, sensitivity $=98 \%$, specificity $=94 \%$; ischaemic heart disease, sensitivity $=93 \%$, specificity $=81 \%$ breast cancer, sensitivity $=81 \%$, specificity $=83 \%$; colorectal cancer, sensitivity $=96 \%$

specificity $=88 \%$, with an area under the receiver operating characteristic curve of 0.90 for males and 0.89 for females.

\section{Conclusion}

This brief self-completed FHQ shows good diagnostic accuracy for identifying people at higher risk of four common chronic diseases. It could be used in routine primary care to identify patients who would be most likely to benefit from a more detailed pedigree and risk assessment, and consequent management strategies.

\section{Keywords}

breast cancer; colorectal cancer; ischaemic heart disease; diabetes mellitus, type 2; family history; primary health care; risk assessment.
INTRODUCTION

The family medical history is traditionally part of history taking in clinical practice but it remains underutilised for diagnostic assessment and disease prevention in routine primary care. ${ }^{1,2}$ In the US in 2007 , an expert panel concluded that tools for systematic collection of family history are likely to improve on usual practice in primary care. ${ }^{3}$ In the UK, despite the emphasis on the need for integration of genetics into primary care, in the Department of Health's 2003 white paper on genetics, the collection and use of family history information continues to present real challenges for GPS. ${ }^{4,5}$ This is partly due to the competing demands for care and time factors that are placed on GPs.6,7 Other challenges include the lack of systematic, computerised, and updateable collection and assessment methods, ${ }^{8}$ the complexity of familial risk interpretation, and concerns about the accuracy of self-reported family history.

A positive family history is an independent risk factor for many common chronic diseases, such as cardiovascular diseases, diabetes, and many cancers, depending on the number of affected relatives and their age at diagnosis. ${ }^{10}$ The family history

FM Walter, MD, FRCGP, clinical lecturer in general practice; L Birt; PhD, research associate; HC Morris, PhD, senior research associate S Sutton, PhD, professor of behavioural science, Department of Public Health and Primary Care, University of Cambridge, Cambridge. AT Provost, $\mathrm{PhD}$, professor of medical statistics, King's College London, Department of Primary Care and Public Health Sciences, Capital House London. N Grehan, research nurse; K Restarick, research nurse; S Downing, MST, RN, RM, genetic nurse counsellor, Addenbrooke's Hospital Cambridge University Hospitals NHS Foundation Trust,

Cambridge. P Rose, MD, FRCGP, senior clinical researcher, Department of Primary Health Care Sciences, University of Oxford, Oxford. JD Emery. DPhil, Winthrop professor of general practice. represents not only shared genetic factors but also environmental and behavioural exposures. It is increasingly seen in public health as a useful tool to identify higher-risk groups to target risk prevention, ${ }^{11}$ although there is little evidence yet to confirm the clinical utility or health benefits of screening family history in primary care. ${ }^{12}$ Nevertheless, clinical guidelines in the UK and internationally recommend family history assessments for many common chronic diseases, such as cardiovascular disease, and there is accumulating evidence about effective interventions for primary or secondary prevention, including behaviour change advice, ${ }^{13}$ early surveillance, and medication. ${ }^{14}$

The authors' previous systematic review of family history questionnaires (FHQs) designed for clinical use showed that they can be used to obtain reasonably accurate family history information, and to identify populations at increased risk of disease. ${ }^{15}$ However, despite the abundance of available FHQs, it highlighted a dearth of FHQs that had been formally validated. Several short single-cancer-specific FHQs existed but the majority were lengthy and derived from the clinical genetics setting. ${ }^{16}$ This study aimed to develop and evaluate

School of Primary Aboriginal and Rural Health Care University of Western Australia, Australia. Address for correspondence

Fiona M Walter, The Primary Care Unit, Department of Public Health and Primary Care, University of Cambridge, Cambridge, CB1 8RN UK E-mail: fmw22amedschl.cam.ac.uk

Submitted: 26 September 2012; Editor's response: 9 December 2012; final acceptance: 30 January 2013

\section{British Journal of General Practice}

This is the full-length article (published online 28 May 2013) of an abridged version published in print. Cite this article as: $\mathbf{B r} \mathbf{J}$ Gen Pract 2013; DOI: 10.3399/bjgp13X668186 


\section{How this fits in}

Family history is an important risk factor for many common diseases but it is underutilised in primary care. The study identified a brief, self-completed family history questionnaire with good diagnostic accuracy for identifying people at higher risk of diabetes, ischaemic heart disease, breast cancer, and colorectal cancer due to their family history. It could be routinely used, either alone or together with assessment of other risk factors, to promote chronic disease prevention.

a brief and simple self-completed family history screening tool for systematic family history assessment in primary care. As approximately $40 \%$ of the adult primary care population will have a family history of type 2 diabetes, ischaemic heart disease, breast cancer, or colorectal cancer, ${ }^{17}$ and there are risk-reducing interventions for these conditions, they were chosen as the marker conditions for this study.

\section{METHOD}

The study was set in 10 general practices in Cambridgeshire, north Essex, mid-Essex, and Hertfordshire primary care trusts between July 2009 and March 2011. The study comprised two consecutive stages (stage 1: development; stage 2: validation), each of which used a different practice population; the recruitment, consultation, and data-collection processes were conducted identically during both stages of the study.

The electronic medical records of each practice were searched to identify all patients aged 18 to 50 years, and an integrated electronic program was then used to randomly sample a group of patients linitially 1000 per practice per stage). Patients were excluded by their GPs if they had insufficient understanding of English, or ongoing serious physical or psychological conditions. Patients were then sent a letter of invitation to take part in a data-collection session arranged in their own surgery.

\section{Family history questionnaire (FHQ)}

The development of the $F H Q$ was informed by the authors' previous systematic review of published research of formally evaluated questionnaire-based approaches to collecting family history in a clinical setting. ${ }^{15}$ The review also informed the format and precise wording of the $F H Q$, which initially comprised 12 items with binary responses relating to family history of type 2 diabetes, ischaemic heart disease, breast cancer, or colorectal cancer. Some items were designed to be simpler but potentially less specific, while other items implemented rules from National Institute for Health and Care Excellence (NICE) guidelines, ${ }^{18}$ aiming to increase the specificity of the tool without loss of sensitivity. In addition, specific ethnicity questions were included, to identify populations at risk of certain inherited forms of chronic disease (for example, Ashkenazi Jewish ancestry and family history of breast cancer to assess the possibility of BRCA mutation carriers). A face validation exercise was also undertaken: the panel of lay members made a number of constructive comments, which were incorporated into the final version.

\section{The reference standard}

While accepting the limitations inherent in a self-reported family history, a threegenerational pedigree collected by a trained research nurse represented the most accurate family history that could pragmatically be obtained in primary care. The researcher assessed the risk of each marker condition, guided by the most recent and relevant evidence appraisals or guidelines: the recommendations of The Fourth Joint Task Force of European and other Societies on coronary heart disease prevention for risk of diabetes and heart disease, ${ }^{19}$ and NICE and Public Health Genetics Unit (eastern region) guidelines for the risk of breast and colorectal cancer. ${ }^{18}$ Cases that could not be assigned to risk categories by the researchers were reviewed by the clinical risk-assessment group, which reached full agreement by consensus.

\section{Data collection}

Two specifically trained nurse researchers with experience in pedigree taking and genetic counselling conducted research data-collection sessions in each participating practice; stages 1 and 2 each lasted about 4 months in each practice. The study consultation lasted 15 to 30 minutes. After giving informed consent, the participant self-completed the $F H Q$ and sealed it in an envelope. The researcher then took a three-generational pedigree as the reference standard, specifically seeking relatives affected with the marker conditions. Based on this pedigree, the researcher gave the participant an estimate of whether they were at normal ['population'] or increased risk for each marker condition. 
Within 1 week, the researcher mailed the participant their full risk assessment based on their family history, plus management recommendations for those found to be at increased risk, including: a nurse visit for diagnostic tests (measurement of blood pressure, blood glucose, lipids) or a GP visit for consideration of referral for cancer screening tests. Copies of these letters plus pedigrees were sent to each participant's GP.

\section{Sample size}

The sample size was calculated using data on the prevalence of family history risk for each marker condition. Six hundred participants per stage was chosen because this provided a very high probability (>90\% power) of identifying whether those answering 'yes' to a questionnaire item would have a different risk from those answering 'no'. For increased diabetes risk (prevalence 18\%), there was $97 \%$ power to detect a relative risk of $2.0130 \%$ at raised risk in those answering 'yes' versus 15\% for those answering 'no'); for increased ischaemic heart disease risk (prevalence $13 \%$ ), there was $92 \%$ power to detect a relative risk of 2.5 (25\% for 'yes' versus $10 \%$ for 'no'); for increased breast cancer risk (prevalence $6.3 \%$ ), there was $95 \%$ power to detect a relative risk of $4.0116 \%$ for 'yes' versus $4 \%$ for 'no'); and for increased colorectal cancer risk (prevalence 2.5\%), there was $93 \%$ power to detect a relative risk of $6.017 .5 \%$ for 'yes' versus $1.25 \%$ for 'no'). These calculations were made for items where $20 \%$ of participants answer yes'. A type 1 error rate of $10 \%$ was used, which provided a safety net to allow

\section{Table 1. Characteristics of participants in stage 1: development stage; stage 2: validation stage; and combined stages}

\begin{tabular}{lccc} 
Characteristic & $\begin{array}{c}\text { Stage 1: } \\
\text { development, } \\
\boldsymbol{n = 6 1 8}\end{array}$ & $\begin{array}{c}\text { Stage 2: } \\
\text { validation, } \\
\boldsymbol{n = 5 2 9}\end{array}$ & $\begin{array}{c}\text { Combined } \\
\text { stages, } \\
\boldsymbol{n}=\mathbf{1 1 4 7}\end{array}$ \\
\hline Practices $(n=10)$, number of participants (range) & $21-98$ & $25-92$ & $21-98$ \\
\hline Participants & $420(68.0)$ & $367(69.4)$ & $787(68.6)$ \\
$\quad$ Female, $n(\%)$ & $41.1(7.6)$ & $41.9(7.0)$ & $41.5(7.3)$ \\
\hline Mean age (SD), years & $114 / 608(18.8)$ & $99 / 519(19.1)$ & $213 / 1127(18.9)$ \\
\hline Prevalence of increased risk of: $n(\%)$ & $80 / 617(13.0)$ & $72 / 527(13.7)$ & $152 / 1144(13.3)$ \\
$\quad$ Diabetes & $26 / 411(6.3)$ & $22 / 361(6.1)$ & $48 / 772(6.2)$ \\
Ischaemic heart disease & $13 / 617(2.1)$ & $12 / 527(2.3)$ & $25 / 1144(2.2)$ \\
Breast cancer & 59.8 & 58.8 & 59.4 \\
Colorectal cancer & & & \\
Population risk for all conditions, \% & &
\end{tabular}

a Practice data: List size (2009) - range 6355 to 19 791; mean = 9870. Location - urban 4; suburban 2; rural 4. Partnership size - range 4 to 12 , mean $=7$. Ethnic minorities - range $2.5 \%$ to $3.9 \% . S D=$ standard deviation. borderline significant items in stage 1 to progress to fuller evaluation in stage 2 .

\section{Statistical analysis}

The aim of the first stage was to identify items, or combinations of items, that were sufficiently predictive of increased risk of each condition to be retained for fuller evaluation and validation in the second stage. In the first step of their evaluation, items were identified as not significant and excluded by using Fisher's exact test of association with $P>0.1$. For consistency, this same exact test method was used for all items, including those items with categories with a small number of responses where only exact methods are valid. All rare response items were excluded at this initial step. A 'positive response' for a combination of items was defined when at least one of the items in the combination was answered yes'. For each condition, the significant item with the greatest accuracy, defined as the average of sensitivity and specificity, was identified and retained. In the second step of the evaluation, each other significant item was excluded if, in combination with the most accurate item, there was no significant improvement in prediction as assessed by the likelihood ratio test. Further steps, using multiple logistic regression, were not reported because once the two items with greatest accuracy were retained, other items did not significantly add to the performance. An exception was to allow a borderline item to be retained for colorectal cancer, in view of the low prevalence of this marker condition.

Validation of the retained items and combinations was assessed by $\chi^{2}$ tests, showing non-significant differences in sensitivity and specificity between the two stages (data available from the authors). Data from the two stages were therefore pooled, and the positive and negative likelihood were reported as an overall assessment for each condition. The positive predictive value and false-positive rate were used to show the posterior probabilities of being at increased risk, given a positive or negative response to the item or combination. The area under the receiver operating characteristic (ROC) curve was obtained using multiple logistic regression, and was used to summarise the performance of applying the overall tool of six items for predicting increased risk for any of these conditions for females, and for the three conditions relevant to males.

\section{RESULTS}

In total, 23175 patients from 10 practices 


\section{Box 1. The Family History Questionnaire (FHQ-12) used in stage 1: development stage}

This risk assessment focuses mainly on your close relatives, including parents, children, brother(s), and sister(s), both living and dead.

\section{Question number}

1 Do you think that there are any conditions or illnesses that run in your family? If so, please specify:

2 Have any of your close relatives, including parent(s), children, brother(s), or sister(s), had heart disease lalso known as cardiovascular disease, heart attack, angina, bypass surgeryl before the age of 60 ?

3a Have any of your close relatives, including parent(s), children, brother(s), or sister(s), had diabetes (also known as type 2 diabetes or non-insulin-dependent diabetes)?

4 Do you come from any of the following ancestry? People from these backgrounds may be at increased risk of diabetes

(a) South East Asia

(b) Indian subcontinent, that is, India, Pakistan, Bangladesh

5 Have any of your close male relatives, including father, son(s), or brother(s), had prostate cancer before the age of 60 ?

6a Have any of your close female relatives, including mother, daughter(s), or sister(s), had ovarian cancer?

7 Have any of your close relatives, including parent(s), children, brother(s), or sister(s), had breast cancer before the age of 50 ?

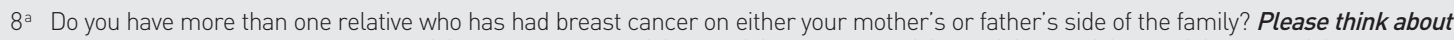
all of the following relatives: parent(s), children, brother(s), sister(s), grandparent(s), aunt(s), uncle(s), niece(s), nephew(s), and grandchildren.

$9 \quad$ (a) Is your family of Jewish ancestry?

(b) If so, are they from Eastern or Central Europe (Ashkenazi)?

People from these backgrounds may be at increased risk of breast cancer

10a Have any of your close relatives, including parents(s), children, brother(s), or sister(s), had colon or rectal cancer lalso known as large bowel or colorectal cancer) before the age of 55 ?

11 a Do you have more than one relative who has had colon or rectal cancer on either your mother's or father's side of the family? Please think about all of the following relatives: parent(s), children, brother(s), sister(s), grandparent(s), aunt(s), uncle(s), niece(s), nephew(s), and grandchildren.

12 On either of your mother's or father's side of the family, thinking about the following relatives: parent(s), children, brother(s), sister(s), grandparent(s), aunt(s), uncle(s), niece(s), nephew(s), and grandchildren, do you have more than one relative who has had: (a) Any cancer?

(b) Any of the following types of cancer: brain, kidney, thyroid, stomach, uterus/endometrial, pancreas?

were approached and 1147 participated (stage 1: 618; stage 2: 529), giving a response rate of $5.0 \%$. The participants were mainly female $(68.6 \%)$, with a mean age of 41.5 years. Overall, $68 \%$ were not at increased risk of any of the marker conditions. The prevalence of increased risk for the marker conditions ranged from approximately $2 \%$ to $19 \%$ (diabetes $18.9 \%$, ischaemic heart disease $13.3 \%$, breast

Table 2. Stage 1: development of brief FHQ-12: performance of each item to detect increased risk of marker condition

\begin{tabular}{|c|c|c|c|c|c|c|c|c|}
\hline \multirow[b]{3}{*}{ Question number ${ }^{\mathrm{a}}$} & & & \multicolumn{4}{|c|}{ Increased risk } & & \\
\hline & \multicolumn{2}{|c|}{ Diabetes } & \multicolumn{2}{|c|}{ Ischaemic heart disease } & \multicolumn{2}{|c|}{ Breast cancer } & \multicolumn{2}{|c|}{ Colorectal cancer } \\
\hline & $\begin{array}{c}\text { Sensitivity, } \\
\%(n)\end{array}$ & $\begin{array}{c}\text { Specificity, } \\
\%(n)\end{array}$ & $\begin{array}{c}\text { Sensitivity, } \\
\%(n)\end{array}$ & $\begin{array}{c}\text { Specificity, } \\
\%[n]\end{array}$ & $\begin{array}{c}\text { Sensitivity, } \\
\%(n)\end{array}$ & $\begin{array}{c}\text { Specificity, } \\
\%(n)\end{array}$ & $\begin{array}{c}\text { Sensitivity, } \\
\%(n)\end{array}$ & $\begin{array}{c}\text { Specificity, } \\
\%[n]\end{array}$ \\
\hline 1 & $80(91 / 114)$ & $34(168 / 491)$ & 81 (64/79) & $33(177 / 535)$ & $88(23 / 26)$ & $27(103 / 382)$ & $77(10 / 13)$ & $31(189 / 601)$ \\
\hline 2 & $37(42 / 113)$ & $72(354 / 494)$ & $92(74 / 80)$ & $79(425 / 536)$ & $35(9 / 26)$ & $70(267 / 384)$ & $15(2 / 13)$ & $70(420 / 603)$ \\
\hline 3 & $98(112 / 114)$ & $94(461 / 493)$ & $36(29 / 80)$ & $77(412 / 536)$ & $23(6 / 26)$ & $74(286 / 384)$ & $38(5 / 13)$ & $75(455 / 603)$ \\
\hline 5 & $4(4 / 113)$ & $97(473 / 490)$ & $4(3 / 80)$ & $97(514 / 532)$ & $4(1 / 25)$ & $97(372 / 384)$ & $0(0 / 13)$ & $96(578 / 599)$ \\
\hline 6 & $5(6 / 113)$ & $96(474 / 494)$ & $6(5 / 80)$ & $96(515 / 536)$ & $28(7 / 25)$ & 97 (374/385) & $0(0 / 13)$ & 96 (577/603) \\
\hline 7 & $10(11 / 114)$ & $93(461 / 494)$ & $8(6 / 80)$ & $93(498 / 537)$ & $50(13 / 26)$ & $95(367 / 385)$ & $8(1 / 13)$ & $93(560 / 604)$ \\
\hline 8 & $18(20 / 113)$ & $85(417 / 493)$ & $24(19 / 78)$ & $85(456 / 537)$ & $73(19 / 26)$ & $84(321 / 384)$ & $15(2 / 13)$ & $84(504 / 602)$ \\
\hline 10 & $6(7 / 113)$ & $94(460 / 491)$ & $5(4 / 76)$ & $93(502 / 537)$ & $7(2 / 26)$ & $95(363 / 382)$ & $85(11 / 13)$ & $96(573 / 600)$ \\
\hline 11 & $16(18 / 113)$ & 89 (439/492) & $16(12 / 77)$ & $89(477 / 537)$ & $12(3 / 26)$ & $88(338 / 384)$ & $54(7 / 13)$ & $89(535 / 601)$ \\
\hline $12 \mathrm{a}$ & 73 (82/113) & $31(150 / 491)$ & $67(53 / 79)$ & $30(158 / 533)$ & $100(26 / 26)$ & $31(120 / 382)$ & $77(10 / 13)$ & $30(181 / 599)$ \\
\hline $12 \mathrm{~b}$ & $31(33 / 107)$ & $72(334 / 467)$ & $31(23 / 74)$ & $72(364 / 509)$ & $58(14 / 24)$ & $73(267 / 366)$ & 25 (3/12) & $71(406 / 571)$ \\
\hline
\end{tabular}

Questions $4 a, 4 b, 9 a$, and $9 b$ are not reported as the numbers were small. 


\section{Table 3. Stage 1: performance of items and their combinations identified to be significant through use of multiple logistic regression analysis}

\begin{tabular}{lccc} 
Condition at increased risk & $\begin{array}{c}\text { Question number } \\
\text { or combination }\end{array}$ & Sensitivity, $\%(\boldsymbol{n})$ & Specificity, \% $(\boldsymbol{n})$ \\
\hline Diabetes & 3 & $98(112 / 114)$ & $94(461 / 493)$ \\
\hline Heart disease & 2 & $92(74 / 80)$ & $79(425 / 536)$ \\
\hline Breast cancer & 8 & $73(19 / 26)$ & $84(321 / 384)$ \\
& 6 & $28(7 / 25)$ & $97(374 / 385)$ \\
\hline Colorectal cancer & 8 and 6a & $92(24 / 26)$ & $81(311 / 384)$ \\
& 10 & $85(11 / 13)$ & $96(573 / 600)$ \\
& 11 & $54(7 / 13)$ & $89(535 / 601)$ \\
& 10 and $11^{\text {b }}$ & $100(13 / 13)$ & $86(515 / 599)$ \\
\hline
\end{tabular}

${ }^{a}$ Combination of questions 6 and 8 is significantly more predictive than question $8(P<0.001) .{ }^{b}$ Combination of questions 10 and 11 is non-significantly more predictive $(P=0.12)$ and retained for further assessment in stage 2 specificity $=94 \%$, and question 2 alone accurately identifies people at an increased risk of ischaemic heart disease (sensitivity $=92 \%$, specificity $=79 \%$ ). For breast cancer, question 8 alone performs fairly well in the identification of females at an increased risk (sensitivity $=73 \%$, specificity $=84 \%$ ); question 6 is more specific (97\%), although it has a low sensitivity of $28 \%$. For colorectal cancer, question 10 alone accurately identifies people at an increased risk (sensitivity $=85 \%$, specificity $=96 \%$ ); question 11 also has high specificity (89\%), although it has lower sensitivity (54\%).

Table 3 shows that combining question 6 with question 8 more accurately identifies females at increased risk of breast cancer (sensitivity $=92 \%$, specificity $=81 \%$ ), and combining question 10 with question 11 more accurately identifies people (males and females) at increased risk for colorectal cancer (sensitivity 100\%, specificity 86\%). These six items lquestions 2, 3, 6, 8, 10, and 11) were therefore taken into the brief $F H Q$.

\section{Stage 2: validation and performance of the brief FHQ}

Validity was high, as shown by the absence of significant differences in sensitivity or specificity for any condition between stage 1 and stage 2. Table 4 shows the combined results for the six items from stages 1 and 2 . Compared with the gold standard pedigree, the brief FHQ ( 6 items) performed very well for all four conditions: pooled data from both stages show diabetes sensitivity $=98 \%$ ( $95 \%$ confidence interval $[\mathrm{Cl}]=95 \%$ to $99 \%$ ), specificity $=94 \%(95 \% \quad \mathrm{Cl}=92 \%$ to $95 \%)$; ischaemic heart disease sensitivity $=93 \%$ $(95 \% \mathrm{Cl}=87 \%$ to $96 \%)$, specificity $=81 \%$ $(95 \% \mathrm{Cl}=79 \%$ to $84 \%)$; breast cancer sensitivity $=81 \%(95 \% \quad \mathrm{Cl}=67 \%$ to $91 \%)$, specificity $=83 \%(95 \% \mathrm{Cl}=80 \%$ to $85 \%)$; colorectal cancer sensitivity $=96 \% \quad 195 \%$ $\mathrm{Cl}=80 \%$ to $99 \%)$, specificity $=88 \% \quad(95 \%$ $\mathrm{Cl}=86 \%$ to $89 \%$ ).

Table 4. Stage 1 and 2 validation of brief FHQ using pooled data

\begin{tabular}{|c|c|c|c|c|c|c|c|}
\hline Condition & $\begin{array}{l}\text { Question } \\
\text { number(s) }\end{array}$ & $\begin{array}{l}\text { Sensitivity, } \\
\%(95 \% \text { CI) }[n]\end{array}$ & $\begin{array}{c}\text { Specificity, \% } \\
(95 \% \text { CI) }[n]\end{array}$ & $\begin{array}{c}\text { Positive } \\
\text { likelihood ratio }\end{array}$ & $\begin{array}{c}\text { Negative } \\
\text { likelihood ratio }\end{array}$ & $\begin{array}{c}\text { Positive } \\
\text { predictive value, \% }\end{array}$ & $\begin{array}{c}\text { False-positive } \\
\text { rate, } \%\end{array}$ \\
\hline Diabetes & 3 & $\begin{array}{c}98 \text { (95 to } 99 \% \text { ) } \\
{[208 / 213]}\end{array}$ & $\begin{array}{c}94 \text { (92 to 95) } \\
\text { [854/913] }\end{array}$ & $15.11^{\mathrm{a}}$ & $0.03^{a}$ & 77.9 & 0.6 \\
\hline Ischaemic heart disease & 2 & $\begin{array}{c}93 \text { (87 to 96) } \\
{[141 / 152]}\end{array}$ & $\begin{array}{c}81 \text { (79 to } 84) \\
{[804 / 990]}\end{array}$ & $4.94^{b}$ & $0.09 a$ & 43.1 & 1.3 \\
\hline Breast cancer & 6 or 8 & $\begin{array}{c}81 \text { (67 to 91) } \\
{[39 / 48]}\end{array}$ & $\begin{array}{c}83 \text { (80 to } 85) \\
{[598 / 723]}\end{array}$ & 4.70 & 0.22 & 23.8 & 1.5 \\
\hline Colorectal cancer & 10 or 11 & $\begin{array}{c}96 \text { (80 to 99) } \\
{[24 / 25]}\end{array}$ & $\begin{array}{c}88 \text { (86 to } 89 \text { ) } \\
{[976 / 1114]}\end{array}$ & $7.75^{b}$ & $0.05^{a}$ & 14.9 & 0.1 \\
\hline
\end{tabular}




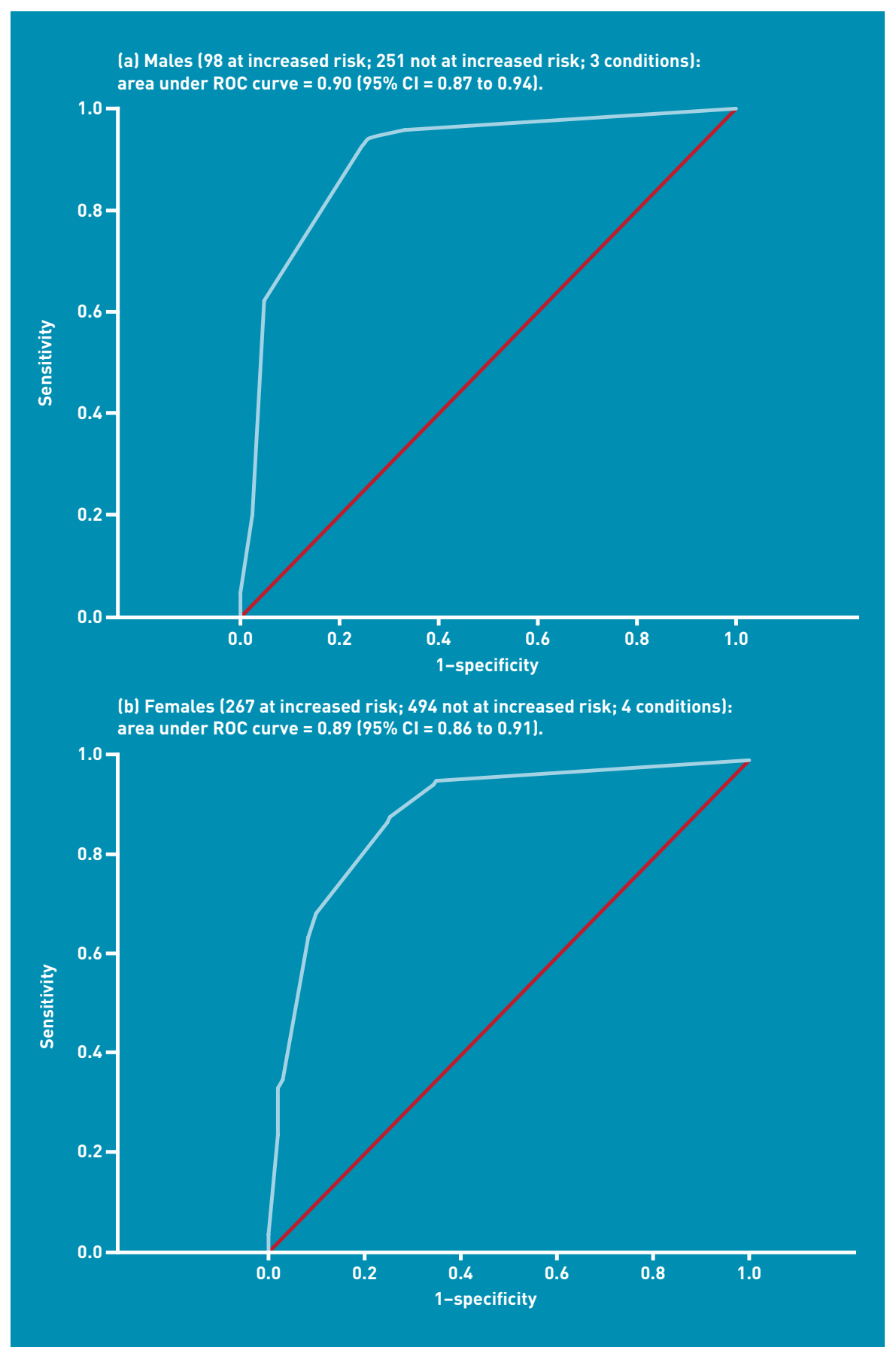

Figure 1. Receiver operator (ROC) curves for (a) males, and (b) females.
Figure 1 shows that the brief $F H Q$ accurately identifies increased risk of any one of the marker conditions in both males and females larea under the ROC curve: males [diabetes, ischaemic heart disease, colorectal cancer $]=0.90[95 \% \mathrm{Cl}=0.87$ to 0.94 ]; females [diabetes, ischaemic heart disease, breast cancer, colorectal cancer $]=0.89[95 \% \mathrm{Cl}=0.86$ to 0.91$]$.

\section{DISCUSSION}

\section{Summary}

This is the first study to validate a short set of questions that simply and accurately predict individuals in primary care at increased risk from their family history of diabetes, heart disease, breast cancer, or colorectal cancer. The brief self-completed tool could be used for common chronic disease prevention in primary care, to identity people who would benefit from more detailed risk assessment and targeted interventions, such as regular colonoscopy or personalised exercise and diet regimes.

\section{Strengths and limitations}

The key strength of this study is that it uses a primary care population to validate generic family history questions and it shows how accurately this short set of questions can identify people at increased risk of four common chronic conditions because of their family history. Recruitment occurred across 10 general practices in eastern England, selected to ensure that people with a broad range of education levels, ethnic origins, and health literacy levels were approached. The sociodemographic data are consistent across both study groups, with stage 2 participants recruited in each practice between 3 and 12 months later than stage 1 participants, suggesting that the participants represent the practice populations. The analytic and reporting approaches were robust and performed according to a quality checklist, the Standards for Reporting of Diagnostic Accuracy (STARD) guidelines. ${ }^{20}$

Although the sample size was sufficient for both stages of this study, the main study limitation is the low recruitment rate, which ranged from $4 \%$ to $7 \%$ across the 10 practices. Members of the target population of people aged between 18 and 50 years were likely to work and have other commitments, which limited their ability to attend a consultation at their surgery during working hours, although early evening appointments were offered to improve recruitment. The focus on risk assessment may not have been of interest to people in good health and without symptoms. A similar recruitment rate was reported in the Family Healthware Impact Trial, which enrolled from primary care practices in the US, to evaluate a self-administered, web-based tool assessing familial risk for coronary heart disease, stroke, diabetes, and colorectal, breast, and ovarian cancers. ${ }^{21}$ Nevertheless, the participants may have been biased towards having an interest or concern about their family history, which reduces the generalisability of the study findings. The selection bias may also have increased the prevalence of 
family history but although this would tend to increase the positive predictive value for each item, the estimates of sensitivity and specificity would remain the same in a primary care population.

\section{Comparison with existing literature}

This study demonstrated a substantial burden of family history risk for these chronic diseases in an adult primary care population in eastern England. The prevalence rates for increased risk for the marker conditions (diabetes $=18.9 \%$, ischaemic heart disease $=13.3 \%$, breast cancer $=6.2 \%$, colorectal cancer $=2.2 \%$ ) are similar to previous reports from the UK population. In comparison, data from the US Family Healthware Impact Trial suggest higher prevalence rates (diabetes $=11 \%$, ischaemic heart disease $=33 \%$, breast cancer $=10 \%$, colorectal cancer $=3 \%$ ), which may be related to their less stringent stratification criteria, ${ }^{22}$ as $82 \%$ of their primary care participants had a 'strong or moderate familial risk for at least one of the diseases', as well as a likely selection bias towards people with a family history of these conditions. ${ }^{21}$

This study has demonstrated the diagnostic accuracy of a self-administered, brief tool compared with the gold standard of a three-generation pedigree, among a population of eastern England. While family history data were not corroborated, for example with cancer registry death certificates, there have been a number of studies suggesting that family history is accurate concerning first-degree relatives and common conditions. ${ }^{9,23}$ Therefore, it is suggested that, once validated among other primary care populations, the tool could be used systematically to increase utilisation of the family history in risk assessment and primary prevention of common chronic diseases in primary care. The ADDFAM (Added Value of ADDing FAMily History) cluster randomised trial, set in England, has recently demonstrated the utility of adding systematic family history enquiry to primary care cardiovascular disease risk assessment. ${ }^{24,25}$ Other studies have also suggested that simple tools can correctly identify the majority of people with a significant family history of coronary heart disease or diabetes, ${ }^{26}$ or colorectal cancer ${ }^{27}$ when compared with a detailed questionnaire. Using brief questionnaires to identify people at higher risk of other diseases such as depression has been established primary care practice for some time. ${ }^{28}$

There is less evidence for the effectiveness of using family history to promote behaviour change among people at risk of common chronic diseases. ${ }^{29}$ The use of family history to promote the uptake of screening for prevention of breast and colorectal cancer has some support, ${ }^{12}$ but the Family Healthware Impact Trial only demonstrated modestly increased self-reported physical activity and fruit and vegetable intake when comparing automated family history assessment and tailored messages with a standard preventive message; furthermore, there was no effect on smoking cessation, aspirin use, or blood pressure or blood glucose screening, and a reduced likelihood of receiving cholesterol screening. ${ }^{30}$

\section{Implications for research and practice}

Further research is needed to ensure that these findings are generalisable to other primary care populations in England and further afield, using similar data-collection and analytic approaches to ensure the quality of reporting diagnostic accuracy; ${ }^{20}$ the findings may also be generalisable to other conditions. Further research could also contribute to establishing the best way for people to use the brief, family history tool: online and smartphone applications could be tested against more conventional paper-based tools. There is also a need to identify whether the tool has utility at patient registration, routine health checks, or opportunistically, although its systematic application as a triaging tool is likely to have most utility, as in the ADDFAM trial. ${ }^{25}$ Certainly, more active approaches to implement the tool, beyond a letter of invitation from a GP, would be required to increase uptake.

This brief self-completed family history screening tool could have important implications for prevention of common chronic disease in clinical practice. While the majority of family history research to date has considered it in isolation from other primary and secondary preventive care, it is likely that using the family history together with other risk factors to promote chronic disease prevention has more acceptability and utility. There are many reports of GPs' resistance to clinical genetics, ${ }^{5,31}$ yet family history questions already contribute to routine symptomatic risk assessment about cardiovascular disease and some cancers. ${ }^{32,33}$ This short tool could therefore be used for triaging healthy, asymptomatic people, in order to reassure those at population risk and to identify those at increased risk who would benefit from further risk assessment and management strategies. 


\section{REFERENCES}

1. Emery JD, Walter FM, Ravine D. Family history: the neglected risk factor in disease prevention. Med J Aust 2010; 192(12): 677-678.

2. Walter FM, Emery JD. Genetic advances in medicine: has the promise been fulfilled in general practice? Br J Gen Pract 2012; 62(596): 120-121.

3. Qureshi N, Wilson B, Santaguida P, et al. Collection and use of cancer family history in primary care. Evidence report/technology assessment No 159. Rockville, MD: Agency for Research Healthcare and Quality, 2007.

4. Department of Health. Our inheritance, our future: realising the potential of genetics in the NHS. CM 5791-II. London: DoH, 2003.

5. McCahon D, Holder R, Metcalfe A, et al. General practitioners' attitudes to assessment of genetic risk of common disorders in routine primary care. Clin Genet 2009; 76(6): 544-551.

6. Guttmacher AE, Collins FS, Carmona RH. The family history - more important than ever. N Engl J Med 2004; 351(22): 2333-2336.

7. Rich EC, Burke W, Heaton CJ, et al. Reconsidering the family history in primary care. J Gen Intern Med 2004; 19(3): 273-280.

8. Plat AW, Kroon AA, Van Schayck CP, et al. Obtaining the family history for common, multifactorial diseases by family physicians. A descriptive systematic review. Eur J Gen Pract 2009; 15(4): 231-242.

9. Murff HJ, Greevy RA, Syngal S. The comprehensiveness of family cancer history assessments in primary care. Community Genet 2007; 10(3): 174-180.

10. Yoon PW, Scheuner MT, Khoury MJ. Research priorities for evaluating family history in the prevention of common chronic diseases. Am J Prev Med 2003; 24(2): 128-135.

11. Wilson BJ, Qureshi N, Santaguida P, et al. Systematic review: family history in risk assessment for common diseases. Ann Intern Med 2009; 151(12): 878-885.

12. Acheson LS. Recording, interpreting, and updating the family history of cancer: implications for cancer prevention. JAMA 2011; 306(2): 208-210.

13. Lancaster T, Stead L. Physician advice for smoking cessation. Cochrane Database Syst Rev 2004; (4): CD000165

14. Jarvinen $\mathrm{H}$, Aarnio M, Mustonen $\mathrm{H}$, et al. Controlled 15-year trial on screening for colorectal cancer in families with hereditary nonpolyposis colorectal cancer. Gastroenterology 2000; 118(5): 829-834.

15. Reid GT, Walter FM, Brisbane JM, Emery JD. Family history questionnaires designed for clinical use: a systematic review. Public Health Genomics 2009; 12(2): 73-83.

16. Qureshi N, Bethea J, Modell B, et al. Collecting genetic information in primary care: evaluating a new family history tool. Fam Pract 2005; 22(6): 663-669.

17. Summerton N, Garrood PV. The family history in family practice: a questionnaire study. Fam Pract 1997; 14(4): 285-288.

18. National Institute for Health and Clinical Excellence. Familial breast cancer, clinical guidelines. London: NICE, 2004

19. Graham I, Atar D, Borch-Johnsen K, et al. European guidelines on cardiovascular disease prevention in clinical practice: full text. Fourth Joint Task Force of the European Society of Cardiology and other societies on cardiovascular disease prevention in clinical practice lconstituted by representatives of nine societies and by invited experts). Eur J Cardiovasc Prev Rehabil 2007; 14(suppl 2): S1-113.

20. Bossuyt PM, Reitsma JB, Bruns DE, et al. Towards complete and accurate reporting of studies of diagnostic accuracy: the STARD initiative. BMJ 2003; 326(7379): 41-44.

21. O'Neill SM, Rubinstein WS, Wang C, et al. Familial risk for common diseases in primary care: the Family Healthware Impact Trial. Am J Prev Med 2009; 36(6): 506-514.

22. Scheuner MT, Wang SJ, Raffel LJ, et al. Family history: a comprehensive genetic risk assessment method for the chronic conditions of adulthood. Am J Med Genet 1997; 71(3): 315-324

23. Janssens AC, Henneman L, Detmar SB, et al. Accuracy of self-reported family history is strongly influenced by the accuracy of self-reported personal health status of relatives. J Clin Epidemiol 2012; 65(1): 82-89.

24. Qureshi N, Dhiman P, Kai J. Adding systematic family history enquiry to cardiovascular disease risk assessment: clinical utility in primary care. Ann Intern Med 2012; 157(2): 149.

25. Qureshi N, Armstrong S, Dhiman P, et al. Effect of adding systematic family history enquiry to cardiovascular disease risk assessment in primary care: a matched-pair, cluster randomized trial. Ann Intern Med 2012; 156(4): 253-262.

26. Wijdenes-Pijl M, Henneman L, Cross-Bardell L, et al. How does a simple enquiry compare to a detailed family history questionnaire to identify coronary heart disease or diabetic familial risk? Genet Med 2011; 13(5): 443-446.

27. Church J, McGannon E. Family history of colorectal cancer: how often and how accurately is it recorded? Dis Colon Rectum 2000; 43(11): 1540-1544.

28. Arroll B, Goodyear-Smith F, Crengle S, et al. Validation of PHQ-2 and PHQ-9 to screen for major depression in the primary care population. Ann Fam Med 2010 8(4): 348-353.

29. Claassen L, Henneman L, Janssens AC, et al. Using family history information to promote healthy lifestyles and prevent diseases; a discussion of the evidence. BMC Public Health 2010; 10: 248.

30. Ruffin MT IV, Nease DE, Jr, Sen A, et al. Effect of preventive messages tailored to family history on health behaviors: the Family Healthware Impact Trial. Ann Fam Med 2011; 9(1): 3-11.

31. Mathers J, Greenfield S, Metcalfe A, et al. Family history in primary care: understanding GPs' resistance to clinical genetics - qualitative study. $\mathrm{Br} J \mathrm{Gen}$ Pract 2010; DOI: 10.3399/bjgp10X501868.

32. Hippisley-Cox J, Coupland C, Robson J, Brindle P. Advantages of QRISK2 (2010): the key issue is ethnicity and extent of reallocation. Heart 2011; 97(6): 515; author reply 15-16.

33. Hippisley-Cox J, Coupland C. Identifying patients with suspected colorectal cancer in primary care: derivation and validation of an algorithm. Br J Gen Pract 2012; DOI: 10.3399/bjgp12X616346. 